\title{
KOMODIFIKASI NILAI ISLAM DALAM FASHION MUSLIM DI INSTAGRAM
}

\author{
${ }^{1}$ Khairul Syafuddin, ${ }^{2} N i^{\prime} a m a t u l ~ M a h f i r o h$ \\ ${ }^{1}$ Kajian Budaya dan Media Sekolah Pascasarjana, Universitas Gadjah Mada \\ ${ }^{2}$ Program Studi Ekonomi Syariah Fakultas Ekonomi dan Bisnis Islam, IAIN Salatiga \\ E-Mail: khairul.syafuddin@mail.ugm.ac.id
}

\begin{abstract}
Abstrak: Salah satu efek dari munculnya teknologi internet adalah lahirnya media sosial. Instagram menjadi media sosial yang hingga saat ini digunakan oleh lebih dari 61 juta orang di Indonesia. Angka tersebut menunjukkan bahwa Instagram telah menjadi alat yang efektif bagi sebuah industri dalam rangka praktik ekonomi politik, salah satunya dalam industri fashion muslim. Salah satu industri fashion muslim yang bergerak di dunia digital adalah santun.inv. Akun tersebut telah membranding dirinya sebagai produsen dari kaos hijrah. Berdasarkan brandingnya serta produk yang dijual melalui akun instagramnya, dapat dilihat bahwa akun tersebut telah melakukan komodifikasi nilai islam melalui alat komoditi fashion. Dengan begitu dapat dilihat, kini nilai islam tidak hanya beroperasi di tataran kajian keilmuan dan dakwah. Namun telah bergeser fungsi menjadi alat ekonomi.
\end{abstract}

Kata kunci: Komodifikasi, Fashion, Instagram, Islam

Abstract: One effect of the development of internet technology is the birth of social media. Instagram is a social media that is currently used by more than 61 million people in Indonesia. The number shows that Instagram has become an effective tool for an industry in the context of political economy practices, one of which is in the Muslim fashion industry. One of the Muslim fashion industries engaged in the digital world is santun. inv. This account has compared him to being a producer of the hijrah shirt. Based on its branding and products sold through its Instagram account, it can be seen in this account that has carried out the commodification of Islamic values through commodity tools. That way it can be seen, now the value of Islam can not only be operated at the level of scientific review and da'wah. But the function has shifted to become an economic tool.

Keywords: Commodification, Fashion, Instagram, Islam

\section{PENDAHULUAN}

Perkembangan di era industri 4.0 ditandai dengan munculnya teknologi internet. Dengan adanya teknologi internet banyak industri yang kemudian berkembang manjadi sangat pesat. Awalnya industri hanya bergerak dengan cara konvensional atau offline. Akan tetapi di era ini, industri juga bergerak di dunia virtual atau online, salah satunya melalui media sosial. Media sosial memungkinkan setiap individu dapat menampilkan identitas dirinya sesuai dengan fantasi yang dimilikinya. Selain itu, mereka juga dapat membentuk hubungan sosial melalui beragam macam fitur yang ditawarkan.

Salah satu media sosial yang banyak digunakan oleh masyarakat di Indonesia adalah Instagram. Instagram merupakan media sosial yang masuk dalam kategori social networking. Nasrullah menjelaskan social networking adalah medium yang digunakan sebagai sarana pengguna 
dalam melakukan hubungan sosial di dunia virtual [1]. Terdapat berbagai macam media sosial yang termasuk dalam social networking, di antaranya Facebook, Twitter, LinkedIn, dan Instagram itu sendiri.

Sebagai media sosial yang banyak digunakan oleh masyarakat, Instagram menyediakan fasilitas berupa tampilan yang lebih berfikus pada visual maupun audio visual daripada captionnya. Hal itu dapat kita lihat secara langsung ketika mulai mengoperasikan media sosial tersebut. Ketika kita membuka Instagram, maka fokus dari hal yang kita konsumsi adalah visual yang disajikan. Hal ini membuat Instagram memiliki keunggulan dalam menampilkan gambar daripada media sosial lainnya.

Menurut tekno.kompas.com jumlah pengguna aktif bulanan di Instagram hingga bulan November 2019 kemarin sebanyak 61.610 .000 orang [2]. Pengguna Instagram ini didominasi oleh 50,8 persen gender perempuan dibandingkan dengan gender laki-laki sejumlah 49, 2 persen. Angka tersebut menunjukkan bahwa Instagram kini telah menjadi media yang populer dan banyak digunakan masyarakat. Sehingga Instagram menjadi efektif ketika dijadikan media untuk advertising maupun campaign.

Salah satu akun yang memanfaatkan kemampuan dan fasilitas Instagram dalam melakukan advertising sekaligus kegiatan campaign nilai keislaman adalah santun.inv. Akun tersebut membranding dirinya sebagai akun hijrah dengan produk utamanya kaos hijrah [3]. Disini sangat terlihat bahwa hijrah yang awalnya digunakan sebagai bentuk dari gerakan islam, kini telah dikomodifikasi, salah satunya oleh akun tersebut.

Vincent Mosco mendefinisikan komodifikasi adalah proses mengubah barang dan jasa yang awalnya dinilai dari sudut pandang kegunaannya, menjadi komoditas yang dilihat dari nilai tukarnya atau sering disebut ekonomi [4]. Dalam hal ini, komodifikasi juga digunakan sebagai salah satu pendekatan dalam media untuk melihat suatu fenomena dari sudut pandang ekonomi politik [5]. Jika dikaitkan dengan fenomena yang ada di Instagram, khususnya pada akun santun.inv, maka dapat dilihat bahwa akun tersebut berusaha menjadikan nilai-nilai keislaman yang mengarah ke hijrah menjadi alat komoditas. Nilainilai keislaman yang telah menjadi alat komoditas tersebut kemudian dimasukkan ke dalam produk fashion, khususnya kaos yang selanjutnya di jual untuk memperoleh keuntungan ekonomi.

Pemilihan fashion oleh akun santun. inv menjadi suatu hal yang cukup cerdas, sebab fashion sebagai pakaian yang dikenakan sehari-hari oleh individu dapat menjadi media komunikasi. Malcolm Barnard dalam bukunya Fashion Sebagai Komunikasi menjelaskan bahwa fashion dan pakaian merupakan bentuk dari komunikasi nonverbal karena tanpa kata-kata secara lisan maupun tertulis [6]. Hanya dengan menggunakan pakaian saja, semua dapat mengkomunikasikan sebuah informasi dan identitas yang ingin ditunjukkan dari diri pemakainya.

Melalui kaos yang dijual oleh santun. inv, dapat dilihat bahwa pemilik akun tersebut ingin membuat agar kaos yang di produksinya dapat mengkomuni-kasikan nilai-nilai keislaman, khususnya dalam gerakan hijrah. Sehingga pada akhirnya setiap konsumen yang mengkonsumsi kaos tersebut dapat berbicara ke arah hijrah melalui pakaian yang dikenakannya tanpa harus menggunakan kata-kata lisan.

Proses komodifikasi ini dapat dilihat bahwa nilai-nilai keislaman, yaitu dalam hal hijrah yang awalnya dilakukan melalui pengajian, khutbah, maupun dakwah secara lisan, telah bergeser ke arah ekonomi politik. Kini hijrah tidak hanya dapat dilihat dari sudut pandang 
nilai keislaman semata. Namun juga dilihat dari segi ekonomi politik. Pemilik akun yang mengambil makna hijrah sebagai produknya secara tidak langsung ingin memperoleh keuntungan ekonomi. Sehingga nilai keislaman kini tidak hanya dapat digunakan untuk menyebarkan kebaikan, tetapi juga dapat dimanfaatkan sebagai alat jual beli.

Penelitian sebelumnya yang dilakukan oleh Baharun dan Niswa (2019) yang berjudul Syariah Branding; Komodifikasi Agama dalam Bisnis Waralaba di Era Revolusi Industri 4.0 melihat bahwa labelisasi syariah digunakan oleh industri sebagai strategi pemasaran untuk menarik konsumen [7]. Hasil dalam penelitian tersebut menunjukkan terdapat bentuk eksploitasi agama. Eksploitasi tersebut menjadi bahan komoditi masyarakat untuk kepentingan dalam mencari keuntungan. Labelisasi syariah itu dilakukan oleh Kopotren Basmalah milik Pesantren Sidogiri dengan tujuan untuk menunjukkan bahwa pesantren mampu bersaing dalam dunia ekonomi. Pesantren tersebut berusaha untuk melakukan modifikasi ilmu agama dan ilmu ekonomi yang akhirnya melahirkan sebuah perusahaan ritel yang berlabelkan syariah.

Kemudian dalam penelitian lain yang dilakukan oleh Aryasatya (2018) yang berjudul Komodifikasi Agama Melalui Iklan Televisi (Studi Kasus Iklan Televisi Berlabel Halal) melihat bahwa ajaran-ajaran agama yang awalnya disampaikan dalam sebuah kajian di masjid telah berpindah menjadi budaya kapital melalui proses komodifikasi [8]. Hal tersebut dilihat melalui iklan yang ditampilkan melalui media televisi. Penelitian tersebut lebih membahas ke arah ajaran islam tentang label halal yang ditunjukkan melalui iklan. Hasil dalam penelitian ini adalah kehadiran islam diterima oleh masyarakat secara taken for granted. Selain itu, agama juga dijadikan alternatif untuk menciptakan identitas baru dan menjadi sebuah kapital simbolik.

Perbedaan penelitian ini dengan kedua penelitian sebelumnnya adalah berkenaan pada objek penelitian. Dalam penelitian sebelumnya, objek yang dilihat adalah iklan pada media massa serta komodifikasi yang dilakukan oleh pondok pesantren. Sedangkan dalam penelitian ini, objek yang diambil adalah salah satu akun dalam media baru (media sosial), dimana pemilik akun belum tentu seorang yang ahli ibadah seperti orang dalam pondok pesantren.

Selanjutnya, dalam penelitian ini peneliti menggunakan teori ekonomi politik yang berfokus pada komodifikasi yang dicetuskan oleh Vincent Mosco. Seperti yang dibahas sebelumnya, bahwa Mosco mendefinisikan komodifikasi sebagai proses perubahan nilai guna menjadinilaitukar.Dalamhalininilaiguna agama, khususnya islam adalah sebagai pedoman kehidupan bagi umat muslim. [9] Kemudian nilai tersebut diubah menjadi nilai guna melalui komoditi kaos atau pakaian yang dijual oleh santun. inv untuk memperoleh keuntungan ekonomi. Sehingga tujuan dari penelitian ini adalah untuk melihat bagaimana nilai-nilai islam dikomodifikasi melalui media sosial Instagram. Tidak hanya komodifikasi dalam bentuk komoditi pakaian, akan tetapi peneliti juga ingin melihat bagaimana komodifikasi nilai islam ini membuat akun santun.inv yang berorientasi pada ekonomi juga berusaha mensyiarkan nilai agama islam.[10]

\section{METODE PENELITIAN}

Penelitian ini menggunakan pendekatan kualitatif dengan paradigma konstruktivisme. Dalam melakukan analisis visual yang ditampilkan dalam akun santun.inv, peneliti menggunakan pendekatan semiotika. John Fiske menjelaskan bahwa model semiotika dapat digunakan dalam produksi 
dan pertukaran makna dalam tataran komunikasi [6]. Sehingga dalam semiotika menaruh perhatian dalam teks yang berinteraksi dengan manusia yang kemudian dapat menghasilkan makna.

Dalam semiotika ini, peneliti menggunakan semiotika model Roland Barthes. Barthes menjelaskan bahwa bahasa merupakan sistem tanda yang mencerminkan asumsi-asumsi dari suatu masyarakat tertentu dalam kurun waktu tertentu [11]. Hal tersebut menunjukkan lingkungan tempat peneliti berada dapat mempengaruhi pemaknaan dalam analisis semiotika. Selain itu, kapan analisis tersebut dilakukan juga menjadi aspek dalam menentukan pemaknaan dari peneliti.

Dalam semiotika Roland Barthes dipengaruhi oleh sistem pemaknaan denotatif, konotatif, dan mitos. Pada tataran denotatif sendiri, terdapat penanda (signifier) dan petanda (signified) yang membentuk tanda denotatif (denotative sign). Selanjutnya petanda denotatif (denotative signified) akan menjadi penanda konotatif (connotative signifier) yang menghasilkan petanda konotatif. Petanda konotatif ini lah yang menjadi tanda konotatif (connotative sign). [12]

Dalam melakukan analisis tersebut, peneliti akan melihat postingan yang di upload oleh santun.inv, yaitu mulai dilihat dari teks visual kaosnya hingga teks naratif kalimat yang dimunculkan. Hal tersebut dilakukan untuk melihat keterkaitan antara visual dan narasi yang ditunjukkan oleh akun santun.inv. Selain itu analisis ini dilakukan untuk melihat bagaimana akun tersebut berusaha mengubah nilai-nilai keislaman menjadi sebuah alat komoditi.[10]

\section{HASIL DAN PEMBAHASAN}

Berdasarkan hasil analisis dan observasi online yang dilakukan oleh peneliti untuk melihat praktik komodifikasi dari akun instagram santun. inv, peneliti melihat bahwa akun tersebut membranding dirinya sebagai pusat dari produksi kaos hijrah. Akan tetapi disini peneliti melihat, alat komoditi untuk melakukan praktik komodifikasi nilai keislaman tidak hanya dilakukan melalui produk kaosnya. Akan tetapi akun tersebut juga memanfaatkan produk lainnya yang ditempelkan dengan nilai keislaman, yaitu melalui produk miki hat dan tumbler.

Dalam menganalisis produk kaos dari akun santun.inv, peneliti mengambil tiga sampel postingan yang telah di upload di feed-nya. Selain itu, peneliti juga mengambil sampel dari produk miki hat dan juga produk tumbler.

Pertama, yang ditampilkan melalui gambar 1 yaitu kaos putih dengan ditempelkan logo Indomie, dimana isi teksnya di ubah menjadi Istiqomah Not Instan. Selanjutnya model yang memakai kaos tersebut ditampilkan seorang anak muda berumur sekitar 20 tahun. Pemilihan kaos dengan warna putih memberikan kesan bahwa istiqomah merupakan sebuah kesucian ketika dihubungkan dengan nilai keislaman. Selanjutnya ketika yang memakai kaos adalah anak muda, maka dapat dilihat bahwa pesan yang ingin disampaikan bahwa anak muda perlu memiliki nilai keislaman, yaitu istiqomah. 


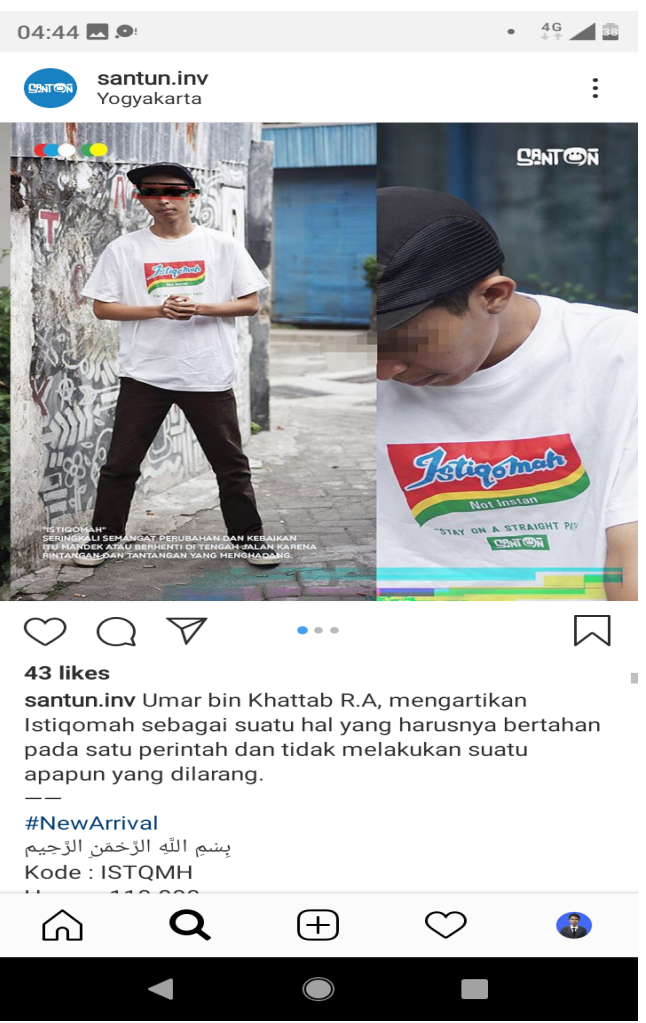

Gambar 1. Produk Kaos Istiqomah

Sumber: www.instagram.com/santun.inv/

Kedua, yang ditampilkan dalam gambar 2 yaitu kaos hitam dengan tulisan faedah yang meniru logo facebook. Pemilihan warna hitam dapat dimaknai bahwa kaos tersebut memiliki makna yang elegan. Dimana nilai keislaman yang berkaitan dengan faedah, berusaha ditempelkan dengan sikap yang elegan. Model yang memakai kaos tersebut juga seorang anak muda yang artinya nilai faedah dalam islam juga mesti dimiliki oleh anak muda.

Ketiga, ditunjukkan melalui gambar 3 yang memperlihatkan seorang model anak muda mengenakan kaos warna abuabu dengan logo Tawakal. Warna abu-abu tersebut memberikan makna bahwa dalam nilai keislaman tentang tawakal, pemilik akun ingin menampilkan bahwa anak muda yang berkeinginan untuk taubat merupakan seoarang yang intelek dengan masa depan yang terukur dan memiliki kesederhanaan. Hal itu sesuai dengan nilai keislaman tentang taubat yang harus ditanamkan pada generasi hijrah.

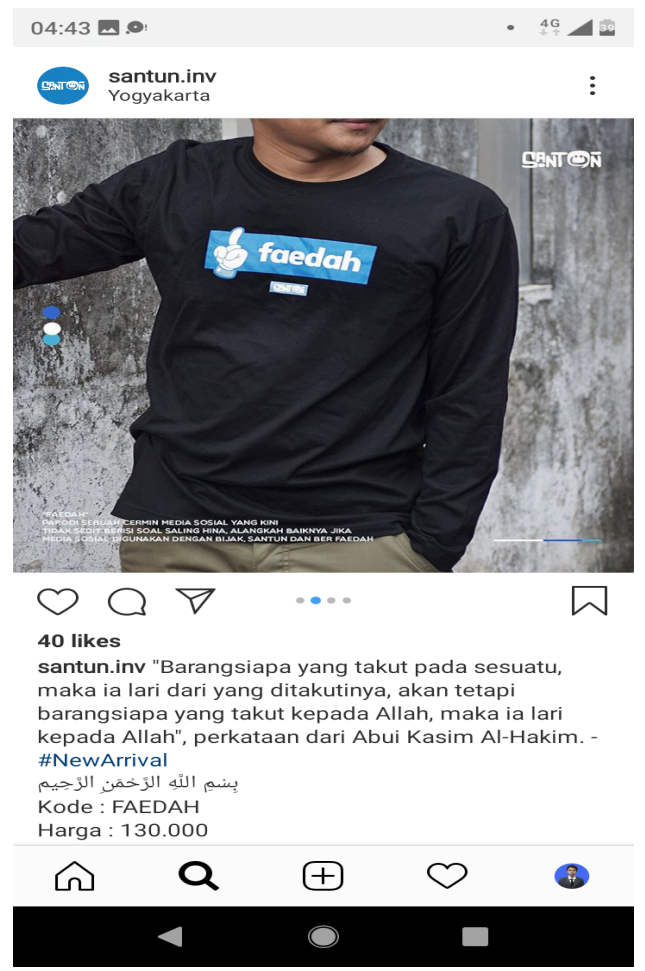

Gambar 2. Produk Kaos Faedah

Sumber: www.instagram.com/santun.inv/

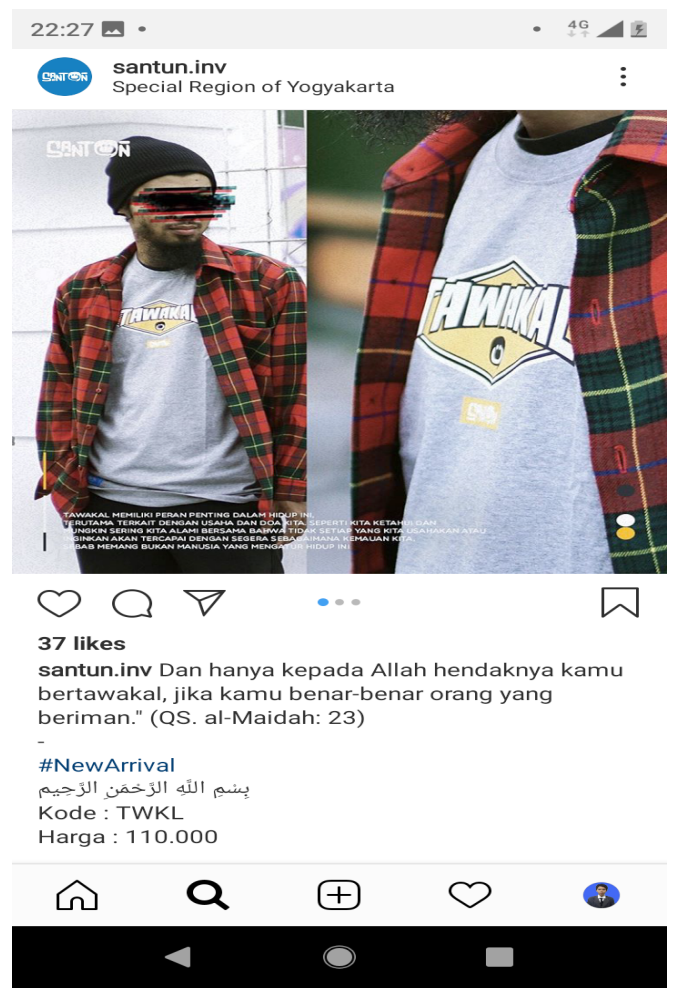

Gambar 3. Produk Kaos Taubat Story Sumber: www.instagram.com/santun.inv/ 
Berdasarkan temuan peneliti yang telah di ambil menjadi beberapa sampel, selanjutnya akan di bahas dalam sub bab berikut.

\section{Komodifikasi Nilai Islam}

Berdasarkan hasil temuan peneliti, dapat dilihat bahwa dalam ketiga produk kaos yang menjadi alat komoditi tersebut memperlihatkan adanya praktik komodifikasi nilai islam. Praktik komodifikasi ini dilakukan dengan mengubah nilai guna dari nilai-nilai keislaman menjadi nilai tukar untuk memperoleh keuntungan ekonomi [5].

Indonesia sebagai negara yang mayoritas penduduknya Islam, membuat banyak produk kemudian dihubungkan dengan nilai keislaman.[13] Secara tidak disadari, dapat dilihat bahwa telah banyak nilai agama yang kemudian dibalut dengan kapitalisme dan menjadi alat komoditas [4]. Komersialisasi dari nilai keislaman sebenarnya telah banyak ditemukan dalam kehidupan sehari-hari umat muslim di Indonesia, mulai dari kata halal, syariah, dan kini merujuk pada berbagai kata dalam nilai keislaman yang ditempelkan pada kaos produksi dari santun.inv.

Komodifikasi nilai islam ini tidak hanya ditempelkan pada kaos oleh santun. inv saja, akan tetapi juga ditempelkan pada miki hat (gambar 4) dan tumbler (gambar 5). Hal ini menunjukkan bahwa pada era ini, komodifikasi nilai keislaman dalam balutan kapitalisme semakin meluas. Praktik dari dakwah kini tidak lagi sekedar melakukan pengajian ataupun kultum di dalam masjid [8], akan tetapi juga melalui praktik komodifikasi, dengan menempelkan nilai keislaman pada alat komoditas, seperti yang dilakukan oleh santun.inv.

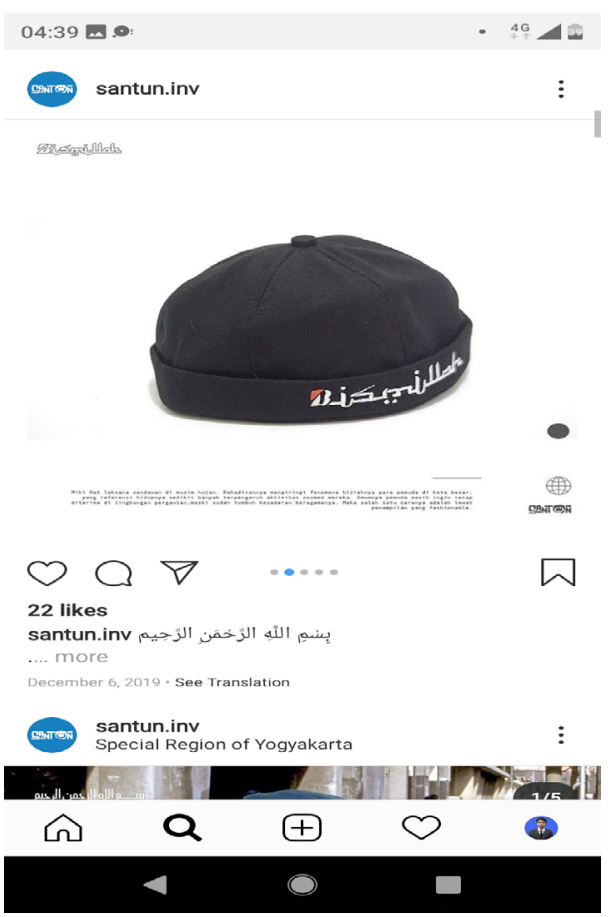

Gambar 4. Produk Miki Hat Bismillah

Sumber: www.instagram.com/santun.inv/

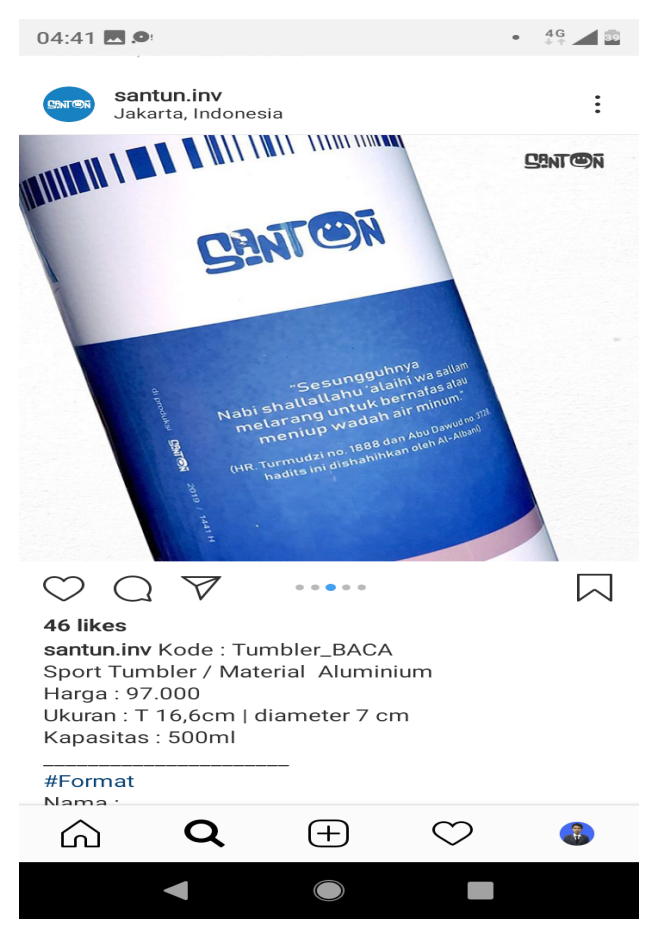

Gambar 5. Produk Tumbler BACA

Sumber: www.instagram.com/santun.inv/

Dalam melakukan komodifikasi nilai keislaman di Indonesia melalui produk 
kaos, hal ini merupakan suatu strategi bisnis yang cukup efektif melihat kondisi Indonesia yang mayoritas muslim, terlebih Indonesiajuga menaruh perhatian khusus pada fashion [4]. Di Indonesia, telah banyak brand muslim yang terkenal, beberapa di antaranya yang di muat dalam artikel www.mocoo.id ${ }^{1}$ dengan judul 10 Merk Baju Muslim yang Terkenal di Indonesia [14]. 10 merk tersebut adalah segelintir merk fashion yang terkenal di Indonesia dan semuanya melakukan praktik komodifikasi nilai keislaman. Guna memperoleh keuntungan ekonomi, mereka berusaha untuk mempresentasikan seperti apa pakaian muslim yang seharusnya dikenakan.

Akan tetapi berbeda dengan apa yang dilakukan oleh santun.inv. Perusahaan yang membranding dirinya sebagai kaos hijrah ini hanya memainkan kata-kata yang memiliki nilai keislaman pada produk kaos, ataupun miki hat dan tumblernya. Ketiga produk tersebut sebenarnya adalah produk biasa yang bisa ditemui di mana saja. Akan tetapi santun.inv berusaha untuk membangun pasarnya sendiri melalui kemampuan sharing dari media Instagram.

Santun.inv melakukan komodifikasi nilai keislaman hanya dengan modal menempelkan kata yang memiliki makna hijrah pada produknya. Selanjutnya mereka mengkaitkannya dengan teks yang ditampilkan dalam postingannya berdasarkan kata yang di pilih. Dari postingannya tersebut, kemudian diperkuat melalui hadits yang disematkan pada caption postingannya tersebut.

\section{Syiar Nilai Keislaman Melalui Produk Komoditi}

Apa yang dilakukan oleh santun. inv tidak hanya praktik komodifikasi nilai keislaman untuk memperoleh keuntungan ekonomi semata. Akan tetapi di dalamnya, akun ini juga sekaligus

\footnotetext{
1 https://www.mocoo.id/baju-muslim-yang-terkenal/
}

terlihat berusaha untuk menyebarkan nilai keislaman dari kata yang diambilnya tersebut. Hal ini terlihat dari setiap visual postingannya, akuninijuga menyematkan teks dalam gambarnya. Adapun beberapa teks yang ditampilkan berdasarkan gambar yang di ambil oleh peneliti adalah sebagai berikut.

"Seringkali semangat perubahan dan kebaikan itu mandek atau berhenti di tengah jalan karena rintangan dan tantangan menghadang." (Gambar 1 Istiqomah)

"Parodi sebuah cermin media sosial yang kini tidak sedikit berisi soal saling hina, alangkah baiknya jika media sosial digunakan dengan bijak, santun, dan berfaedah." (Gambar 2 - Faedah)

"Tawakal memiliki peran penting dalam hidup ini. Terutama terkait dengan usaha dan doa kita. Seperti kita ketahui dan mungkin sering kita alami bersama bahwa tidak setiap yang kita usahakan atau inginkan akan tercapai dengan segera sebagaimana kemauan kita, sebab memang bukan manusia yang mengatur hidup ini." (Gambar 3 - Tawakal)

Ketiga teks tersebut terbentuk melalui sistem dari nilai keislaman. Seperti istiqomah yang memiliki makna untuk terus berusaha tanpa putus asa dalam nilai keislaman. Faedah merupakan bentuk dari kegiatan yang memiliki manfaat dalam pandangan islam. Serta tawakal yang dalam islam memiliki makna berserah diri kepada Allah ketika semua usaha dan doa telah dilakukan. Semua itu telah menjadi bahasa yang tersistem berdasarkan nilai keislaman di luar dari bahasa individu, seperti yang dijelaskan oleh Saussure.

Ketiga nilai di atas juga menjadi sebuah tindakan dari individu. Hal ini dilihat dari setiap postingan dan kata 
yang disematkan dalam kaos tersebut, membentuk teks yang menunjukkan suatu tindakan. Seperti istiqomah yang dalam teks di atas sebagai bentuk tindakan dari kaum muda untuk terus berjuang tanpa lelah meski terdapat rintangan yang menghadang. Kemudian faedah yang dikaitkan dengan penggunaan media sosial agar digunakan secara bijak dan bermanfaat. Serta tawakal yang menjadi bentuk kegiatan individu dalam berdoa dan berusaha dengan berpasrah kepada Allah. Ketiga makna tersebut pada akhirnya menjadi satu kesatuan dalam tindakan hijrah. Dalam hal ini hijrah yang di syiarkan oleh akun santun.inv adalah hijrah dari perbuatan yang buruk ke arah perbuatan yang baik. [15]

Disamping penyematan teks pada visual atau gambar yang menjadi postingan di feed akun santun.inv, dapat dilihat bahwa pada caption postingan tersebut juga diberikan sebuah hadits pendukung. Hadits ini digunakan untuk memperkuat pesan dalam syiar nilai islamnya. Hal ini menunjukkan bahwa selain bertujuan untuk membuat nilainilai islam menjadi alat komoditas untuk memperoleh keuntungan ekonomi, akun santun.inv melalui media Instagramnya juga berusaha untuk tetap mensyiarkan nilai keislaman, khususnya dalam gerakan hijrah melalui postingannya. Sebab tidak semua brand atau produk yang mengkomodifikasikan nilai Islam kemudian juga turut berusaha mensyiarkan nilai-nilai di dalamnya. Akan tetapi akun ini terlihat berusaha untuk tetap mensyiarkan nilai-nilai tersebut melalui postingannya.

\section{KESIMPULAN}

Berdasarkan hasil dan pembahasan tersebut peneliti menyimpulkan bahwa akun santun.inv menggunakan 3 barang komoditi dalam mengkomodifikasi nilai keislaman, yaitu kaos, miki hat, dan tumbler. Berbeda dengan kebanyakan brand muslim yang terkenal. Akun ini memilih barang komoditi tersebut sesuai dengan gaya anak muda di era sekarang. Dimana ketiga barang tersebut merupakan barang yang dikenakan atau dikonsumsi sehari-hari tanpa terbatas oleh keadaan.

Komodifikasi yang yang dilakukan oleh santun.inv berupa penempelan kata yang memiliki nilai keislaman yang mengarah pada kegiatan hijrah. Dimana ketika kata tersebut mereka tempelkan pada barang yang menjadi komoditinya, kemudian mereka berikan mekna dalam postingan di akunnya sehingga membentuk suatu identitas tertentu. Akan tetapi identitas yang ditunjukkan melalui fashion tersebut hanya berkenaan pada kegiatan hijrah. Sehingga disini nilai hijrah yang memiliki makna berpindah dari hal buruk menjadi lebih baik dalam pandangan islam, mereka ubah menjadi nilai jual untuk memperoleh keuntungan.

Selain itu, peneliti juga melihat bahwa akun tersebut tidak hanya ingin melakukan komodifikasi dan mencari keuntungan melalui nilai keislaman semata. Akan tetapi mereka juga tetap berusaha mensyiarkan nilai islam melalui postingannya. Hal tersebut terlihat dari teks yang disematkan dalam gambar postingannya yang diperkuat melalui hadits yang menjadi caption-nya.

Dikarenakan penelitian ini hanya melihat pada sudut pandang teksnya saja, sehingga saran peneliti untuk penelitian berikutnya adalah penelitian ini dapat dilihat berdasarkan sudut pandang komunikator maupun komu-nikannya. Sehingga hasil yang diperoleh dalam melihat proses komodifikasi dari nilai keislaman tersebut menjadi lebih kuat. 


\section{DAFTAR PUSTAKA}

[1] R. Nasrullah, Media Sosial Perspektif Komunikasi, Budaya dan Sosioteknologi. Bandung: Simbiosa Rekatama Media, 2016.

[2] tekno.kompas.com, "Sebanyak Inikah Jumlah Pengguna Instagram di Indonesia?," 2019. .

[3] santun.inv, "SANTUN.INV | Kaos Hijrah," 2019. .

[4] R. T. Arianti and H. Purnama, "Komodifikasi Kata Halal pada Iklan Hijab Zoya Versi Cantik Nyaman Halal," J. Lingk. Stud. Komun., vol. 4, no. 2, pp. 160-169, 2018.

[5] K. Syafuddin and R. Andreas, "Komodifikasi Nasionalisme Dalam Iklan Sirup," in The 7th Urecol, 2018, vol. 7, pp. 245-258.

[6] M. Barnard, Fashion Sebagai Komunikasi Cara Mengkomunikasikan Identitas Sosial, Seksual, Kelas, dan Gender, 2nd ed. Yogyakarta: Jalasutra, 2009.

[7] H. Baharun and H. Niswa, "Syariah Branding; Komodifikasi Agama dalam Bisnis Waralaba di Era Revolusi Industri 4.0," INFERENSI J. Penelit. Sos. Keagamaan, vol. 13, no. 1, pp. 75-98, 2019.

[8] A. B. A. Aryasatya, "Komodifikasi Agama Melalui Iklan Televisi (Studi Kasus Iklan Televisi Berlabel Halal)," J. Pustaka Ilm., vol. 4, no. 1, pp. 515-523, 2018.

[9] S. shobron Muthoifin and S. A. Rahman, "Humanist islam in indonesia ahmad syafii maarif perspective," Humanit. Soc. Sci. Rev., vol. 7, no. 6, pp. 780-786, 2019, [Online]. Available: https://giapjournals.com/index.php/hssr/article/view/ hssr.2019.76118/2384.

[10] M. Sudarno Shobron, Amrin, Imron Rosyadi, "Islamic Education Values in the Tradition of Peta Kapanca of Mbojo Community Tribe in West Nusa Tenggara," Int. J. Adv. Sci. Technol., vol. 29, no. 5, pp. 6802-6812, 2020.

[11] A. Sobur, Semiotika Komunikasi, 5th ed. Bandung: PT Remaja Rosdakarya, 2015.

[12] Muthoifin, "Shariah hotel and mission religion in surakarta indonesia," Humanit. Soc. Sci. Rev., vol. 7, no. 4, pp. 973-979, 2019, doi: 10.18510/hssr.2019.74133.

[13] A. S. Sudarno Shobron, Mutohharun Jinan, MA Fattah Santoso, Muthoifin, "Contribution Boarding Schools For Social Changes In Central," Int. J. Psychosoc. Rehabil., vol. 24, no. 06, pp. 7851-7859, 2020, [Online]. Available: https://www. psychosocial.com/article/PR260794/19358/.

[14] www.mocoo.id, "10 Merk Baju Muslim yang Terkenal di Indonesia," 2019. .

[15] B. P. Muthoifin, "Readiness Towards Halal Tourism in Indonesia Perspective of Reality and Religion," Int. J. Adv. Sci. Technol., vol. 29, no. 8, pp. 862-870, 2020. 